\title{
Patrimônio em movimento: considerações sobre o mundo rural paulista
}

Heritage on the move: considerations on rural paulista

\author{
Mirza Pellicciotta \\ Doutoranda em História Cultural (Unicamp) e coordenadora \\ do Departamento de Turismo da Prefeitura Municipal de Campinas \\ E-mail: mirzapellicciotta@yahoo.com.br
}

\section{RESUMO}

Este artigo procura refletir brevemente sobre a trajetória de constituição e transformação do território paulista entre os séculos XVI e XXI na busca de contribuir para a identificação e reconhecimento de diferentes paisagens culturais, gestadas em recortes de tempo e espaço específicos e que ainda hoje guardam testemunhos inestimáveis do patrimônio rural paulista. $\mathrm{O}$ artigo procura também traçar algumas considerações sobre as fazendas integrantes do projeto Fazendas Históricas Paulistas.

Palavras-chave: Território; Cultura paulista; Patrimônio rural

\section{Abstract}

This article attempts to reflect briefly on the history of formation and transformation of the state area between the XVI and XXI in the quest to contribute to the identification and recognition of different cultural landscapes, gestated in nippets of time and space specific and still keep that invaluable testimonies paulista rural heritage. The article also seeks to draw some considerations about the farms involved in the project farms state history.

Keywords: Territory; Culture São Paulo; Rural heritage 


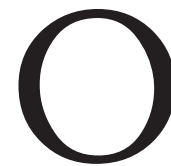

território de São Paulo contém, em seu interior, diferentes paisagens culturais... paisagens que, constituídas no curso do tempo, sofreram transformações profundas nos últimos séculos frente aos processos acelerados de substituição da cobertura vegetal pela produção diversificada de gêneros, criação e agricultura de exportação; pela entrada massiva de grupos populacionais procedentes das mais variadas regiões do Brasil e do mundo (cerca de 70 grupos étnicos); pela intensidade da urbanização (séculos XIX e XX); pela complexificação dos sistemas de escoamento (estradas tropeiras, linhas férreas, estradas de rodagem, aviação), entre outros, que permitiram a então Capitania, depois Província e atual Estado vencer a Serra do Mar (que a mantivera isolada da dinâmica colonial ao longo dos séculos XVI a XVIII) e estabelecer vínculos comerciais e produtivos entre as regiões mais interiorizadas e o litoral.

Particularmente nos últimos cento e sessenta anos, a intensidade e força de certos processos em grande medida externos ao território paulista se revelaram capazes de apagar (nos limites entre dizimar e incorporar) a presença milenar de populações indígenas, ao mesmo tempo que diluir marcas centenárias de constituição cultural original (indígenas e européias) para dar lugar a paisagens plenamente alteradas em suas bases econômicas, sociais, culturais e políticas originais. A expressão "paulista”, utilizada para caracterizar um povo diferente pelos hábitos, língua, costumes e formas de vida mestiça, passou em pouco tempo a designar uma população disforme pelos tantos aspectos culturais, vínculos e motivações agora associadas ao capital transnacional.

De qualquer forma, foi nos percursos de ocupação (e transformação) dos vários "sertões" do planalto paulista que ganhou lugar paisagens culturais específicas, podendo-se vislumbrar através delas a formação e transformação da Capitania, Província e Estado de São Paulo. A história paulista, por isso mesmo, pode ser entendida em meio a constituição e desenvolvimento de diferentes unidades internas dotadas de formas e ritmos próprios que, no curso do tempo, dariam lugar a cenários ou paisagens diferentes, muitas vezes marcadas por dinâmicas externas à própria região, Estado e País.

Os estudos acerca do patrimônio rural paulista realizados pelo projeto Fazendas Históricas Paulistas e fundamentados num conjunto de 14 
1 - Marcos de formação/ transformação da região metropolitana de Campinas à luz da história territorial paulista: séculos XVII/XX. Aula elaborada para o projeto Geotecnologias como apoio à elaboração de material didático para o ensino fundamental: Atlas Ambiental Escolar da Região Metropolitana de Campinas sob coordenação de Cristina Criscuolo. CNPM / Centro Nacional de Pesquisa de Monitoramento por Satélite. 2010

\section{2 - Mirza}

Pellicciotta. O Alto e Médio Tocantins em Tempo e Espaço de transformação. Subsídios históricos para o "Projeto Peixe Angical". Empresa Documento Arqueologia e Antropologia. São Paulo, 2000/2001. Texto inédito com registro de direito autoral na Biblioteca Nacional. fazendas, exigiram/vem exigindo dos pesquisadores envolvidos uma grande atenção com as particularidades presentes na esfera dos municípios, das regiões e das propriedades, além de um considerável esforço de articulação e síntese entre/das propriedades na busca de compreendê-las como parte de um território comum.

\section{SOBRE OS SERTÕES PAULISTAS}

Antes de mais nada, devemos considerar que a constituição do território paulista é obra centenária. Nos primeiros séculos de ocupação e colonização, as terras paulistas abarcavam áreas hoje pertencentes aos Estados de Minas Gerais, Goiás, Mato Grosso, Rio Grande, Santa Catarina e ainda no século XIX, ao Paraná. Um vastíssimo território que, à semelhança de outras porções da América Portuguesa, ganharia forma na medida em que os colonizadores portugueses penetrassem pelos sertões valendo-se da capacidade de trocar/incorporar conhecimentos com povos milenarmente integrados a um território desconhecido e perigoso. (CUNHA, 1998)

A penetração, conquista e permanência portuguesa nestes sertões se faria/se manteria ao custo da transformação de ambos os povos sobreviventes, (MONTEIRO, 1994) sedimentando-se um percurso contínuo de (re)conquistas de um vasto território ocupado, bem como a constituição de uma sociedade mestiça e atenta em fazer avançar a colonização sobre outros "sertões". (HOLANDA, 1957)

Por outro lado, as trajetórias de ocupação também se definiram em associação direta com a manutenção - ou não - de laços entre o mundo colonial e o mundo metropolitano, [1] e neste caso, a penetração/ocupação do território paulista adquiriu características específicas ao se dar mais "isolada" do mundo metropolitano. (TAUNAY, 1950) As limitações impostas pela serra do mar deram lugar a uma economia modesta e ao desenvolvimento de uma sociedade itinerante que no curso dos séculos XVI, XVII e parte do XVIII alcançou regiões localizadas na atualidade, nos estados do Mato Grosso, Goiás, Minas Gerais, Paraná, Santa Catarina e Rio Grande do Sul, [2] nelas originando as bases de uma cultura regional que se tornaria conhecida como "caipira". 
Os primeiros núcleos de povoamento e tentativas de fixação européia no território paulista ocorreram entre os séculos XVI e XVII na região litorânea, em áreas que hoje englobam os municípios de Paranaguá (PR), Morretes (PR), Antonina(PR), Cananéia, Iguape, Peruíbe, Itanhaém, São Vicente, Santos, Guarujá, São Sebastião e Ubatuba. Nestes séculos surgiram também núcleos de povoamento no planalto, associados a aldeamentos (em especial, jesuíticos), a instalação de fazendas (com suas capelas de devoção) e entrepostos comerciais - hoje em dia localizados no município de São Paulo e em suas imediações, nos municípios de Cotia, Carapicuiba, Barueri, Embu, São Roque, Santana do Parnaíba, Pirapora do Bom Jesus, Araçariguama, Itu, Salto, Porto Feliz, Sorocaba, Piracicaba, Mogi das Cruzes, Guararema, Ribeirão Pires, São Luiz do Paraitinga, Atibaia, Jundiaí, Taubaté, Itaquaquecetuba, Iporanga, Nazaré, Jacareí, Cabreúva, Registro, Lapa (PR). (PETRONE, 1995) Nos dois primeiros séculos, o povoamento das terras paulistas fez-se restrito a uma área de até $100 \mathrm{~km}$ da atual capital (Taubaté, 1636) e com cerca de $60 \mathrm{~km}$ de raio (Jundiaí, Parnaíba, Itú, Sorocaba e Atibaia). (MATOS, 1991)

No século XVIII, os processos de penetração apresentaram mudanças. De fato, desde a segunda metade do século XVII, a circulação de paulistas pelos sertões mais interiorizados havia lhes possibilitado identificar veios auríferos em áreas que posteriormente integrariam o Estado de Minas Gerais. A criação de inúmeros arraiais e a prática de mineração por paulistas ainda no final do século XVII redundaria em conflitos com outros interesses da Metrópole Portuguesa que, já nas primeiras décadas do século XVIII, incorporaria este território como Real. Limitados em suas atividades, os paulistas orientariam suas incursões por regiões ainda mais distantes, conseguindo realizar novas descobertas auríferas (atuais estados de Goiás e Mato Grosso), seguidas pela criação de novos arraiais, pela prática da mineração e pelo estabelecimento de uma rota fluvial regular de abastecimento - a "Rota das Monções" -, criada com a intenção de preservar algum domínio sobre as regiões.

A "Rota das Monções" interligava o povoado de Araraitaguaba (Porto Feliz) às regiões auríferas de Mato Grosso pelos rios Tietê, Paraná, Ivinhema ou Pardo, e por meio deles a um "varadouro" que os conduzia à bacia do 
Rio Paraguai. Por meio dela, os paulistas instituíram uma nova modalidade de penetração ao aliar tradições bandeiristas às demandas de abastecimento, conseguindo importantes resultados. Esta dinâmica de penetração, no entanto, motivaria em pouco tempo a criação, pela Metrópole Portuguesa, de novas Capitanias: além da Capitania de Minas Gerais, seriam formadas as Capitanias de Goiás, de Mato Grosso, do Rio Grande e de Santa Catarina, seguindo-se a anexação (provisória) dos sertões paulistas ao governo da Capitania do Rio de Janeiro (1748/1765) e, por fim, o restabelecimento da Capitania paulista com seu território reduzido a um terço das proporções originais.

Com os limites circunscrito, a partir de 1765, a oeste pelo Rio Paraná, ao norte pelo Rio Grande e ao sul pela área correspondente ao Estado do Paraná, seu novo território em formato triangular continuava a contar com a principal artéria de penetração paulista, o Rio Tietê, (PETRONE, 1968) ao mesmo tempo em que a constituição de Capitanias propriamente auríferas traria desdobramentos importantes para o mundo paulista. Sua criação impulsionaria a migração de populações de diferentes regiões da colônia (Maranhão, Piauí, Bahia, Rio de Janeiro, entre outras) na mesma proporção em que estimularia os núcleos paulistas a direcionar parte de sua produção de abastecimento a um mercado interno em crescimento. Os desdobramentos não tardariam a chegar; não apenas os paulistas intensificaram a produção e transporte de gêneros, como outras populações passaram a penetrar o território paulista para atender as mesmas demandas, resultando daí uma transformação ainda mais profunda dos caminhos de desenvolvimento paulista.

Em particular, a expansão dos negócios de abastecimento das minas ocupou um lugar importante na constituição "moderna" do Estado de São Paulo: o desenvolvimento de atividades agro-pastoris somado à penetração e fixação de um forte e contínuo contingente de mineiros traria mudanças profundas no sistema de ocupação e produção original, reforçando progressivamente as relações de mercado no trato da terra, das criações e do atendimento aos viajantes. De fato, uma nova economia de subsistência, fundada num outro sistema e dinâmica de posses, de pastagens e criações associados diretamente às relações mercantis, passa- 
va a se contrapor a uma maneira paulista tradicional de habitar os sertões que até então atuara como verdadeira barreira ao fortalecimento das relações de mercado, fundada na agricultura itinerante e no convívio mais ou menos violento com etnias indígenas.

De forma concomitante, uma nova dinâmica migratória mostravase intensa e passava a registrar em pouco tempo uma sucessão de posses e/ou sesmarias integradas a "pousos" na margem dos caminhos mais importantes, como a "Estrada dos Goiases", que mais se assemelhavam a fazendas especializadas "em atender aos viandantes e às tropas que seguiam pelo caminho". Na condição de verdadeiras unidades produtivas, elas mantinham roçados de mandioca, cana, feijões, bananas, algodão, milho, e frequentemente contavam com campos de pastagem e criação de gado vacum, cavalar e suínos, oferecendo não apenas sustentação para a estrada mas desenvolvimento econômico para a Capitania (autores dos entrantes do rio pardo).

Estas atividades de abastecimento nas paragens passaram, pouco a pouco, a estabelecer relações com outras paragens e a promover uma dinamização comercial entre atividades e localidades, transformando-se antigas "bocas de sertão" em "paragens de viajantes", ou ainda, em localidades (povoados) estruturadas em "pequenas e médias unidades produtoras dedicadas a diversas atividades voltadas para o auto-abastecimento, para o mercado interno e, mais tarde, para o mercado externo" que atuariam como "novas fronteiras". (MESSIAS, 2003:20/21)

SOBRE OS CAMINHOS, PICADAS E PICADÕES NOS/DOS SERTÕES PAULISTAS

Para alcançar as minas de Cuiabá (MS), os paulistas utilizavam de uma rota fluvial, caminho que cumpriria papel central no abastecimento de parte da região centro-oeste. Mas, para chegar às minas de Goiás, faziase necessário seguir - por terra - os passos de seu descobridor, Bartolomeu Bueno da Silva, o "Anhanguera", que também recebera da Coroa Portuguesa o direito de cobrar passagem sobre rios. Nos registros iconográficos do século XVIII, podemos então identificar o traçado da Estrada dos Goiases ou do Anhanguera, caminho que partia de São Paulo rumo a Jundiaí, passava pelo bairro rural de Mato Grosso (Campinas), 
margeava a Serra da Mantiqueira e na altura do "sertão da farinha podre" (triângulo mineiro) tomava a direção oeste rumo às minas de Goiás e Mato Grosso. Aberta a partir do descobrimento das "minas dos goiases" em 1722, a Estrada do Anhanguera merecera, a partir de 1726, a concessão de alguns lotes de sesmarias (doados, inicialmente, aos descobridores das minas de Goiás), seguindo-se, entre os anos de 1728/1735, novas concessões voltadas a fixar "criações de gados e cavalgaduras em terras que se acham devolutas", além de fornecer gêneros, promover a sustentação da estrada e permitir o "aumento na real renda dos dízimos, e taxação aos minérios”. Em 1730, já definida como estrada real, o caminho passara a contar com "registros nos rios, sesmarias ao longo da rota e a instalação de funcionários reais" no controle e cobranças. (BRIOSCHI, 1991:12)

O "Caminho do Anhanguera" ou "Estrada dos Goyases", como se tornou conhecida, acabou de fato por fixar pousos, fazendas de gado e de cavalgaduras (que também forneciam gêneros para a sustentação da estrada), além de promover a instalação de povoados (instalações geralmente precedidas/acompanhadas pela obtenção de sesmarias) tornando-se "razão de existência e (...) sobrevivência" dos "primeiros assentamentos populacionais" (BRIOSCHI 1991) que dariam origem as cidades de Mogi Mirim (1769), Mogi Guaçu (1877), Casa Branca (1841), Batatais (1839), Franca (1821), entre outras. O "Caminho do Anhanguera", na altura do "sertão da farinha podre" também dava acesso a estrada para a comarca do rio das mortes (São João Del Rei) - a "Picada de Goiás” (aberta em fins da década de 1740) - prestando-se a interligar o sul de Minas Gerais ao território goiano. Este caminho possibilitaria aos mineiros disputar com os paulistas o fornecimento de gêneros e criações para os arraiais e vilas goianas e mato-grossenses, auxiliando-nos a compreender o porque do enfraquecimento vivido pela "Estrada dos Goiases" entre as décadas 1740/1800, período no qual praticamente cessaram as distribuições de sesmarias em seu trajeto.

Além desta rota, surgiram outras estradas destinadas a interligar as vilas paulistas com os mercados em desenvolvimento, entre elas: a "Estrada para a Vila da Constituição" - que interligava as vilas de São Paulo a Araritaguaba/Porto Feliz (1797), passando por Itu e Constituição/ 
Piracicaba; a "Estrada para a divisa de Minas Gerais" - que seguia por Juqueri, Atibaia (1769) e Bragança (1797); a "Estrada do Norte de São Paulo"- que interligava São Paulo a Bananal, no Vale do Paraíba, através das atuais Mogi das Cruzes (1611), Jacareí (1653), São José dos Campos (1767), Taubaté (1645), Pindamonhangaba (1705), Guaratinguetá (1651), Lorena (1788), Areias (1816) e Bananal (1832); a "estrada para Ubatuba" (1637), que passava por Santos, São Sebastião e Caraguatatuba (1857); e ainda, o caminho para o Paraná "através de Cotia, São Roque, Sorocaba, Itapetininga e Faxina (atualmente Itapeva)". (MATOS, 2001) Em direção oeste também foram abertos caminhos por terra, entre eles, o "Picadão de Cuiabá”, estrada aberta por ordem governamental em meados do século XVIII, que seguia pela margem direita do Rio Tietê na busca de alcançar os chamados "campos do Araraquara", localizados entre os rios Tietê, Jacaré-Guaçu e Moji-Guaçú, [3] em grande medida desconhecidos.

\section{DE VOLTA AOS SERTÕES PAULISTAS}

No início do século XIX, as atividades agrícolas e criatórias associadas ao mercado interno (desenvolvidas nas proximidades da "Estrada dos Goiases" e dos demais caminhos terrestres e fluviais dos sertões paulistas), ganhariam mais uma especialidade: as lavouras extensivas de cana de açúcar e café, voltadas para o mercado externo.

Estas lavouras tiveram início nas últimas décadas do século XVIII na porção sul da Capitania, no chamado "quadrilátero do açúcar" (formado entre as regiões de Constituição/Piracicaba, Mogi Guaçu, São Carlos/Campinas e Itu), em resposta a um conjunto diverso de fatores econômicos e políticos, entre eles, uma nova política governamental que se voltava a promover a ocupação, produção e povoamento do território através da concessão de sesmarias em regiões consideradas estratégicas, da adoção de medidas para a reestruturação do porto de Santos, da melhoria das vias de comunicação entre o planalto e o litoral, ou ainda, da definição de novas diretrizes de comercialização com a Metrópole.

$\mathrm{Na}$ região de Campinas, os canaviais começaram a chegar nas últimas décadas do século XVIII e em pouco tempo, o montante da produção somado aos recursos por ela obtidos permitiria ao povoado pleitear

\author{
3 - Mirza \\ Pellicciotta. Os \\ Sertões do \\ Paranapanema. \\ Subsídios históricos \\ para o "Projeto \\ Taquaruçu-Sumaré. \\ Linha de \\ transmissão 440 \\ kv". Empresa \\ Documento \\ Arqueologia e \\ Antropologia. São \\ Paulo, 1999. Texto \\ inédito com registro \\ de direito autoral na \\ Biblioteca Nacional.
}


e obter o estatuto de vila (1797), além de receber o título de cidade (1842) quando da substituição das lavouras extensivas de cana de açúcar por café. Na região da atual Piracicaba (Constituição), as plantações de cana tiveram início nos últimos anos do século XVIII, registrando-se três engenhos no ano de 1798 e uma produção de 700 arrobas; estes números subiriam para 115.609 arrobas e 78 estabelecimentos em 1836. (PETRONE 1968) De fato, uma ampla região já se encontrava tomada pelos canaviais nas primeiras décadas do século XIX quando o naturalista francês Saint Hilaire avistou nas imediações da "Estrada dos Goiases", em 1819, uma: “...vasta extensão de terras muito povoadas que, em toda a Província de São Paulo, produz maior quantidade de cana de assucar e compreende as terras de Mogi Mirim, São Carlos (Campinas), Jundiaí, Itu, Capivari, Porto Feliz e Constituição”. (SAINT HILAIRE, 1953) Também, nas áreas paulistas mais interiorizadas como os "campos de Araraquara" as lavouras extensivas de cana - e depois, as de café - passaram a ocupar o lugar da produção dos gêneros alimentícios, tornando-se majoritária por volta de 1850 quando os lucros do açúcar permitiram a importação de alimentos, ainda que à custa de verdadeiros períodos de carestia.

A produção de café, opção às lavouras de cana de açúcar em diversas regiões, impulsionaria ainda mais as lavouras extensivas, desencadeando uma séria disputa por terras (em especial, as ainda ocupadas por etnias indígenas) entre as chamadas "frente de expansão" (com predomínio de atividades de subsistência frente às de troca) e "frente pioneira" (caracterizada por empreendimentos econômicos) nos sertões paulistas, (SOUZA MARTINS 1971) valendo considerar que, em meados do século XIX, a decretação da "Lei de Terras" no território brasileiro traria desdobramentos particulares para a então Província de São Paulo. Esta lei, decretada em 1850, substituía o sistema de sesmarias (interrompido desde 1822) pela regulamentação de contratos de compra/venda de propriedades, ao mesmo tempo em que instituía para áreas consideradas "não ocupadas" a categoria de terra devoluta, colocando "em disponibilidade" para aproveitamento, imensas extensões de terras entre as quais, os territórios indígenas, abrindo outras/novas possibilidades de avanço das frentes "de expansão" e "pioneira" sobre regiões como as de Bauru, que 
desde meados do século XIX passara a abrigar etnias caingangues e otis. (PINHEIRO, 1992)

O desenvolvimento de lavouras extensivas de cana e café, somado a penetração de posseiros/criadores/negociantes de origem mineira por um território já ocupado por etnias indígenas e paulistas/agricultores itinerantes, se traduziria, enfim, num conflituoso processo de posse de terra, sobressaindo-se, de fato, a "marcha do café" em função da velocidade com que este "episódio da civilização capitalista" conseguiria transformar as paisagens paulistas. (MONBEIG, 1984)

A "onda verde", que chegara aos sertões paulistas pelo Vale do Paraíba, penetrava agora pelos contrafortes ocidentais da Mantiqueira (Itu, Jundiaí, Campinas, Amparo, Bragança, São João da Boa Vista, Mococa) e, "aproveitando os afloramentos de terra roxa”, começava a seguir para a depressão periférica através da região ao norte de Campinas (Limeira, Araras, Rio Claro, Leme, Piraçununga e Descalvado). Na antiga região dos "campos de Araraquara", as primeiras mudas de café começaram a ser introduzidas na década de 1830 , enquanto na região da atual São Carlos, a Sesmaria do Pinhal (terras de Antonio Carlos de Arruda Botelho) introduzira o cultivo de 60 mil pés de café na década de 1860; passadas duas décadas, as fazendas do Conde do Pinhal já contabilizavam cinco milhões de pés de café (1878), enquanto as fazendas de Araraquara registravam cerca de dois milhões de pés.

Passadas várias décadas, as plantações de café alcançariam os maciços de Ribeirão Preto (dividido pelo Rio Pardo) e os de Araraquara ambos separados pelo vale do rio Mogi-Guaçu - nas últimas décadas do século XIX, e a partir deles, os cafezais se espalhariam pelas "grandes extensões de terra roxa no planalto ocidental paulista" (de Mococa ao Vale do Paranapanema, acompanhando o escarpamento da cuesta). Identificada por Monbeig como "terceira fase da penetração cafeeira", a produção nesta região contabilizaria no início do século XX, o montante de 110 milhões de cafeeiros no maciço de Ribeirão Preto (entre as terras, ao norte, de Batatais e as terras, ao sul, de Ribeirão Preto, Sertãozinho, São Simão, Cravinhos e Santa Rita do Passa Quatro) e de 100 milhões de cafeeiros no maciço de Araraquara (à esquerda do Rio Mogi-Guaçu, rumo 
as terras de São Carlos do Pinhal, Descalvado, Pitangueiras, Araraquara, Bebedouro e Jaboticabal). Ainda, na zona compreendida entre Araraquara e a calha do rio Tietê (nas proximidades de Jaú e Brotas) se faria presente 70 milhões de pés de café (entre as décadas de 1880 e 1910), e do outro lado do Rio Tietê, na área junto a cuesta, outros 45 milhões de cafezais (nas regiões de Botucatu/São Manoel, com prolongamento para Lençóis, Avaré, Piraju e Salto Grande)... eixo, por sua vez, que começava a aproximar a lavoura cafeeira das imediações de Bauru.

Com tal volume de produção, enfim, seria inevitável que nas últimas décadas do século XIX a economia cafeeira assumisse o centro das atenções, dos investimentos e das relações de poder no território paulista, restando aos criadores de gado e aos lavradores de subsistência - há muito instalados em várias porções do "sertão" -, a alternativa de regulamentar suas "posses" e aderir ao novo processo ou vender suas terras e migrar mais para o oeste... De fato, ambos os fenômenos ganharam lugar e as "bocas de sertão" passaram a se deslocar cada vez mais para oeste (levadas por mineiros), ao mesmo tempo em que novos mineiros, paulistas, cariocas e cidadãos de outras paragens (em especial, portugueses) avançavam pelas terras de mata, consideradas as mais férteis para abrir as lavouras de café.

Em uma perspectiva paralela, a expansão cafeeira patrocinara a chegada da ferrovia na Província/Estado de São Paulo a partir de 1867, e entre os diversos papéis que este empreendimento desempenhou constou a tarefa histórica de vencer o isolamento imposto pela Serra do Mar aos "negócios" paulistas por meio da criação/desenvolvimento de um sistema adequado (seguro, rápido) de transporte de carga e passageiros entre o planalto e o mar. Coube também ao sistema ferroviário acelerar a penetração e transformação de vastas áreas de campo e mata em novas áreas de lavoura, criação e industrialização, potencializando o desenvolvimento, a articulação e a geração de um padrão de ocupação estruturado na monocultura extensiva, na diversificação do capital, na especialização regional e na migração em massa. A história de suas empresas se fez marcada, igualmente, pelas disputas de territórios, pela criação de monopólios e modernização tecnológica, transformando-se o "trem" na pró- 
pria representação de "progresso". O papel desempenhado pela ferrovia no complexo cafeicultor, enfim, acabaria por substituir as centenárias nomenclaturas dos sertões paulistas por nomes de empresas de circulação regional, entre elas, as expressões: "região central" (para a área de Campinas, Porto Feliz, Piracicaba, Indaiatuba, Bragança); "mogiana” (para a área de Mogi Mirim, Mogi Guaçu, Pedreira); "baixa paulista” (para a área de Rio Claro, Araraquara, Limeira); "alta sorocabana” (para uma vasta área com início em Botucatu); "alta paulista e noroeste” (para a área de Bauru).

Entre as últimas décadas do século XIX e as primeiras décadas do século XX, enfim, grande parte da Província/Estado de São Paulo já se achava transformada pela expansão - sem precedentes - da economia cafeeira, segmento agrícola que, ao aprimorar suas relações e vínculos com o mercado, deixara-se (re)organizar como setor produtivo de forma a alcançar os mais altos níveis de qualidade exigidos pelo comércio internacional. Utilizando-se de vastíssimas terras virgens, de força de trabalho abundante (inicialmente escravo, depois livre), de equipamentos especializados, de novas modalidades de transporte e de uma significativa diversificação de capital, a produção do "ouro verde" transformara as paisagens paulistas. $\mathrm{O}$ século $\mathrm{XX}$, neste sentido, começava marcado pelo crescimento acelerado das cidades, ou ainda, pela sedimentação/fortalecimento de suas zonas de produção e circulação. Ao longo das décadas, cada uma destas zonas cafeeiras recebera o apoio, em paralelo a expansão das lavouras, de um conjunto articulado e dinâmico de empreendimentos voltados a assegurar/ampliar a produtividade agrícola, diversificar os investimentos, garantir o abastecimento e a comercialização de gêneros (agrícolas ou não) das próprias regiões. E em meio a essa dinâmica, a fixação de trabalhadores cumpria um papel primordial, a ponto de tornar-se objeto de uma variedade de empreendimentos imobiliários específicos (rurais e urbanos), destinados a orientar esta fixação em diferentes pontos de produção do complexo.

Os trabalhadores trazidos para o território paulista procediam de diversos países e continentes e eles começaram a chegar, em escala massiva, nas últimas décadas do século XIX. Os registros populacionais das déca- 
das de 1850 a 1880 nos revelam um pouco sobre as "realidades" experimentadas por estas pessoas. Eles nos fornecem dados, por exemplo, sobre a convivência que trabalhadores livres e escravos poderiam manter entre si, ou ainda, sobre as regiões a que se destinavam. Neste caso, com base em registros de 1854, 1874 e 1886, podemos observar que os novos trabalhadores escravos se mantiveram concentrados, neste período, nas regiões "central" (38 mil escravos em 1854, 52 mil em 1874, 31 mil em 1886) e "mogiana" (15 mil escravos em 1854, 23 mil em 1874, 21 mil em 1886), encontrando-se em menor número na zona da baixa paulista ( 5 mil escravos m 1854, 15 mil em 1874, 17 mil em 1886) e em pequeno número na zona paulista (2.500 escravos em 1854 e 2600 em 1886). No caso dos trabalhadores livres imigrantes, até o ano de 1886, eles ainda se apresentavam incipientes frente ao volume de trabalhadores escravos, além de, ao contrário dos anteriores, se encontrarem concentrados na "baixa paulista" (7700 imigrantes), na "mogiana" (4900 imigrantes) e na “região central” (4890 imigrantes). (Memória Urbana, 2001)

Entre os anos de 1886 e 1900, período no qual a imigração em massa já se encontrava estabelecida - e em que a escravidão se achava abolida desde as vésperas da decretação da República (1889) -, é possível observar algumas variações entre as regiões no quesito empregabilidade, de fato, são nas "franjas pioneiras" (áreas de desmatamento e abertura de novas plantações) que se encontram as maiores demandas por trabalhadores, sugerindo-nos os números de 1886/1900 que: as zonas central e mogiana ainda se achavam produtivas: suas populações praticamente duplicaramm; que a zona da paulista ocupava o lugar de ponta: sua população quadruplicara; que a zona da "sorocabana" apresentava uma produção e crescimento ainda modestos: sua população crescera cerca de 25\%. Os números de 1920 a 1940 já registram variações: eles nos dizem que as zonas central e mogiana deixaram de contar com uma produção significativa: suas populações não registravam variações; que as zonas paulista e alta sorocabana ainda se achavam produtivas: suas populações praticamente duplicaram; que a zona da "noroeste" ocupava o lugar de ponta: a sua população quadruplicara. (Idem, 2001)

Entre os anos 1901 e 1940, período marcado pela entrada massiva 
de imigrantes, podemos perceber que as regiões apresentam oscilações em suas capacidades de atrair e reter as novas populações; a região central, por exemplo, que recebera 49 mil imigrantes em 1901, registra em 1940 a entrada de apenas 19 mil imigrantes; a "mogiana”, pelo contrário, recebera 155 mil imigrantes em 1901 e em 1940 permanecia atrativa para 118 mil imigrantes. A zona da "baixa paulista" que contara em $1901 \mathrm{com}$ a entrada de 97 mil imigrantes, permanecia em 1940 com a entrada de 74 mil imigrantes, repetindo-se na zona da paulista um volume semelhante: 81 mil em 1901 e 92 mil em 1940. (Ibidem, 2001)

Um outro conjunto de dados nos permite observar a diversidade étnica destas populações, sendo possível constatar, de saída, a presença majoritária de italianos em todas as zonas cafeeiras, entre as décadas de 1920 e 1940; atrás deles viriam os imigrantes espanhóis e portugueses (com números semelhantes), e em menor escala, japoneses e alemães. Estes números, no entanto, revelam variações quando observamos sua distribuição pelas regiões: existem áreas com concentrações étnicas distintas, como a zona central que conta predominantemente com italianos, espanhóis, portugueses, alemães e japoneses; a zona mogiana que concentra, respectivamente, italianos, espanhóis, portugueses, alemães e japoneses; a baixa paulista que apresenta italianos, espanhóis e portugueses (números equivalentes), além de japoneses e alemães. Enfim, para termos uma visão um pouco mais detalhada desta diversidade, uma amostragem de 1934 nos ajuda a perceber que, nesta ocasião na capital e nos sertões paulistas, São Paulo contava com a presença de 300 mil italianos, 176 mil portugueses, 160 mil espanhóis, 131 mil japoneses, 25 mil sírios, 12 mil austríacos, 983 estônios, 3400 franceses, 12800 húngaros, 1800 ingleses, 15600 letos, 9300 russos, 8000 eslavos, 8700 argentinos, 1600 norte americanos, 450 paraguaios e 780 uruguaios. (Ibidem, 2001)

Incorporados por algumas décadas como colonos, este grande e progressivo contingente de imigrantes se transformaria, ao longo do tempo, em pequenos proprietários rurais ou em empregados/trabalhadores urbanos, de diferentes ramos de especialidades e "negócios"; nos "sertões paulistas” do século XX, de fato, torna-se possível extrair lucro das mais variadas frentes..entre elas: da especulação da terra, do cultivo e transfor- 
mação de gêneros de subsistência (farinha, macarrão), da extração e transformação da madeira, do beneficiamento de gêneros de exportação (café, algodão, arroz). E esta diversidade de possibilidades se vincula ao novo padrão (e sentido) de cidade que se fizera emergir; por outro lado, estas características vão possibilitar ao complexo cafeicultor sobreviver a crise da própria economia cafeeira no final da década de 1920, superar e redefinir sem maiores dificuldades seus caminhos de desenvolvimento. A cidade de Campinas pode ser tomada como exemplo: ela não apenas se refez da crise, como redefiniu suas perspectivas de produção e acumulação, passando a assumir, em poucas décadas, um papel revigorado como centro de serviços e geração de ciência e tecnologia no interior paulista.

\section{PATRIMONNIO DOS SERTÕES PAULISTA}

O projeto Fazendas Históricas Paulistas vem conferindo uma significativa atenção aos estudos, discussões e elaboração de propostas na interface entre turismo e preservação, razão de sucessivas e distintas atividades entre pesquisadores (de áreas distintas), técnicos e proprietários, constando entre os resultados, os esforços de aproximar os levantamentos, estudos e análises criteriosos do patrimônio material e imaterial das propriedades rurais, das estratégias, propriamente ditas, de apresentação, desvendamento e compreensão dos processos singulares de constituição, por meio de uma circulação e fruição adequada e coerente com os propósitos maiores de preservação.

$\mathrm{Na}$ busca de estabelecer uma modalidade de turismo patrimonial apropriado à realidade das fazendas históricas paulistas, o sub-grupo de Educação Patrimonial e Turismo avançou nas discussões sobre o esvaziamento das relações produtivas no interior das mesmas propriedades; sobre o interesse e motivação, por parte dos proprietários, de recompôr elementos identitários da fazenda através do resgate de histórias familiares - perspectiva, no entanto, que vem se mostrando insuficiente em vários aspectos, em função das mesmas famílias se acharem distantes do mundo do trabalho rural (dos saberes e fazeres populares, festas, religiosidade, costumes modeladores do espaço produtivo e da paisagem cultural); sobre a importância de restabelecer vínculos entre as propriedades rurais e as populações 
outrora integradas ao espaço produtivo, na perspectiva de reforçar os sentidos de pertencimento entre a propriedade, a população e o município; sobre a necessidade de realizar estudos sobre os públicos de interesse; sobre a importância de estabelecer relações entre os processos de estudo, resgate, interpretação e conservação de bens móveis, imóveis, materiais e imateriais (de caráter permanente), com as ações educativas e modalidades de ação turística; sobre a importância de promover medidas de salvaguarda de bens culturais materiais e imateriais, utilizando-se para tanto das ferramentas de educação patrimonial e turismo; sobre a importância de desenvolver propostas integradas de circulação turística interna e externa (município e região), atentas ao conceito de paisagem cultural; sobre a possibilidade de instaurar no interior de cada propriedade um laboratório de pesquisa (espaço de workshops, de atividades pontuais de conservação e restauro, de oralidade, de ação arquivística, entre outras) atuante, também, como ponto de apoio das ações de educação patrimonial e de turismo histórico-cultural por compreender o visitante como agente da reconstrução e preservação histórica; sobre a necessidade de promover estudos aprofundados acerca da formação e transformação dos municípios no curso do tempo e sobre suas relações com a propriedade rural em estudo; sobre a importância de desenvolver e orientar a instalação de um sistema de sinalização patrimonial de caráter turístico, bem como de materiais turísticos complementares capazes de informar, sensibilizar e orientar o acesso ao patrimônio histórico-cultural e ambiental da propriedade rural à luz da história do município e da região; sobre a importância de contribuir para o fortalecimento das relações entre a propriedade rural e o município através do resgate e valorização identitária do universo rural na formação e transformação urbana.

\section{REFERENCIAS BIBLIOGRÁFICAS}

BACELAR, C. de A. P., Brioschi L. R. (orgs.). Na Estrada do Anhanguera: Uma Visão Regional da História Paulista. São Paulo: Humanitas/CERU, 1999.

BRIOSCHI, Lucila Reis et al. Entrantes no Sertão do Rio Pardo: o Povoamento da Freguesia de Batatais - séculos XVIII e XIX. São Paulo: Ceru, 1991

CUNHA, Manuela Carneiro da (org.). História dos Índios no Brasil. 2 ed. 
São Paulo: Companhia das Letras/Fapesp/Secretaria Municipal de Cultura, 1998

DUTRA, Miguel. O Poliédrico Artista Paulista. São Paulo: MASP, 1981

ELLIS JR, Alfredo. A Economia Paulista no Século XVIII. O Cíclo do Muar, o Cíclo do Açúcar. São Paulo, s/e, 1950

GOULART, José Alípio. Tropas e Tropeiros na Formação do Brasil. Rio de Janeiro: Conquista, 1961

HOLANDA, Sérgio Buarque de. Caminhos e Fronteiras. Rio de Janeiro: José Olympio Editora, 1957

HOLANDA, Sérgio Buarque de. Monções. $3^{a}$ edição ampliada. São Paulo: Brasiliense, 1960

LEITE, Marcelo (org). Nos Caminhos da Biodiversidade Paulista. São Paulo: Secretaria do Meio Ambiente, 2007

MONTEIRO, John Manoel. Negros da Terra: Índios e Bandeirantes nas Origens de São Paulo. São Paulo: Companhia das Letras, 1994

MARTINS, José de Souza. "Frente pioneira - Contribuicao para uma caracterizacão sociológica”. Estudos Históricos, n. 10, p. 3341, 1971

MATOS, O. N. de. Café e Ferrovia. São Paulo: Pontes Editores, 1990.

Memória Urbana: A Grande São Paulo Até 1940. São Paulo: Arquivo do Estado/Emplasa/Imprensa Oficial, 2001

MONBEIG, Pierre. Pioneiros e Fazendeiros de São Paulo. São Paulo: Hucitec/Polis, 1984. 